\title{
Three-dimensional and microstructural fingerprinting of gold nanoparticles at fluid-mineral interfaces of
}

\author{
Haoyang Zhou ${ }^{1, *}$, Richard Wirth ${ }^{1}$, Sarah A. Gleeson ${ }^{1,2}$, AnJa Schreiber $^{1}$, \\ AND SATHISH MaYanna ${ }^{1}$
}

\author{
${ }^{1}$ GFZ German Research Centre for Geosciences, Telegrafenberg, Potsdam 14473, Germany \\ ${ }^{2}$ Institute of Geological Sciences, Freie Universität Berlin, Berlin 12249, Germany
}

\begin{abstract}
Recent studies have identified gold nanoparticles in ores in a range of deposit types, but little is known about their formation processes. In this contribution, gold-bearing magnetite from the welldocumented, world-class Beiya Au deposit, China, was investigated in terms of microstructure and crystallography at the nanoscale. We present the first three-dimensional (3D) focused ion beam/scanning electron microscopy (FIB/SEM) tomography of the distribution of gold nanoparticles in nanopores in the low-Si magnetite. The porous low-Si magnetite, which overprints an earlier generation of silician magnetite, was formed by a coupled dissolution-reprecipitation reaction (CDRR). The extrinsic changes in thermodynamic conditions (e.g., S content and temperature) of the hydrothermal fluids resulted in the CDRR in magnetite and the disequilibrium of Au-Bi melts. The gold nanoparticles crystallized from Au-supersaturated fluids originating from the disequilibrium of Au-Bi melts and grew in two ways depending on the intrinsic crystal structure and pore textures: (1) heteroepitaxial growth utilizing the (111) lattice planes of magnetite, and (2) randomly oriented nucleation and growth. Therefore, this study unravels how intrinsic and extrinsic factors drove the formation of gold nanoparticles at fluid-mineral interfaces.
\end{abstract}

Keywords: Gold nanoparticle, nanopore, fluid-mineral interface, 3D FIB/SEM tomography, microstructure, coupled dissolution-reprecipitation reaction

\section{INTRODUCTION}

Some of the largest Au deposits in the world contain highgrade ores of "invisible" gold (e.g., Carlin-type deposits; Cook and Chryssoulis 1990; Simon et al. 1999b). Based on in situ trace element, spectroscopic, and experimental analyses, it has been suggested that "invisible" gold is often present in the lattice of the ore minerals such as (arsenian) pyrite (Simon et al. 1999a; Reich et al. 2005) and that the partitioning of Au is a function of the As content of the pyrite (Kusebauch et al. 2019; Xing et al. 2019). The final uptake of Au by the pyrite lattice also depends on complex intrinsic (e.g., crystal surface structure, heteroepitaxial growth, and diffusion-limited self-organization) and extrinsic factors (e.g., pressure; Wu et al. 2019).

Recent advances in imaging by transmission electron microscopy (TEM) have shown that "invisible" gold can also exist as nanoparticles in the ore minerals (Palenik et al. 2004; Reich et al. 2006; Ciobanu et al. 2012). Multiple models for the formation of gold nanoparticles in hydrothermal systems have been suggested. These include gold exsolution from solid solution (Palenik et al. 2004), gold saturation during sulfide precipitation (Reich et al. 2005), and gold precipitation from pore-attached

\footnotetext{
* Present address: Natural History Museum, University of Oslo, P.O. Box 1172 , Blindern, 0318 Oslo, Norway. E-mail: haoyang.zhou@nhm.uio.no. ORCID 00000002-0079-503X

Open access: Article available to all readers online.
}

vapors (Ciobanu et al. 2012). However, it can be difficult to discriminate between these models because the textural association of gold nanoparticles with the host minerals is hard to characterize at the nanoscale and is sometimes ambiguous based on two-dimensional (2D) textural analysis (e.g., Godel et al. 2010). Recently, 3D analysis using atom probe tomography (APT) interpreted gold nanoparticles as a growth feature that formed via the diffusion of Au atoms on surfaces of slow-growing sulfides (Fougerouse et al. 2016). However, further investigation of the gold nanoparticles in the ore minerals is required to understand the formation processes at fluid-mineral interfaces, especially utilizing high-resolution and 3D imaging techniques.

Focused ion beam/scanning electron microscopy (FIB/SEM) tomography, also known as FIB/SEM slice and view technology, is a novel and powerful tool for 3D analysis via serial FIB slicing the material followed by SEM imaging. It offers great advantages in both morphological characterization and spatial resolution (down to a few nanometers) and so can be used to characterize the micro- to nanoscale microstructural features of geomaterials (Wirth 2009). Therefore, a combination of high-resolution FIBbased 3D SEM tomography and TEM analysis was used in this study to investigate magnetite containing abundant gold particles from the world-class Beiya Au deposit, Southwest China (Zhou et al. 2017). Integrating the high-resolution $3 \mathrm{D}$ distribution and the crystallographic relationship of gold nanoparticles and nanopores in magnetite, we examine the fluid-mineral interfacial processes responsible for the formation of gold nanoparticles. 


\section{SAMPLE BACKGROUND AND DESCRIPTION}

The 36 Ma old Beiya polymetallic Au deposit in the eastern Jinshajiang fault zone of the eastern Tibetan plateau contains 11.9 million ounces of Au at a grade of $2.52 \mathrm{~g} / \mathrm{t}$ and is the thirdlargest Au deposit in China (Fig. 1; Mao et al. 2017; Zhou et al. 2019). The main mineralization occurs as a skarn and is divided into prograde- and retrograde-stages. The latter is auriferous and can be subdivided into oxide (magnetite-dominated) and sulfide (pyrite- and chalcopyrite-dominated) stages (Zhou et al. 2016, 2017). At least $14 \%$ of the total Au endowment is hosted by magnetite, but it has not been extracted (Zhou et al. 2017). From the oxide to sulfide stages, the ore-forming fluids evolved from hypersaline, high temperature $\left(\sim 360-510{ }^{\circ} \mathrm{C}\right)$ to lower salinity, lower temperature $\left(\sim 165-350{ }^{\circ} \mathrm{C}\right)$ conditions, which is attributed to the ingress of meteoric water into the magmatic system (He et al. 2017).

Two magnetite gold ores (Au-1 and $\mathrm{Au}-2$ ) sampled from the Beiya deposit were used in this study. Au-1 comes from orebody KT52 (the largest Au orebody at Beiya) in the Wandongshan open-pit (E100'11'33", N26 10'3", 1630 m altitude), whereas $\mathrm{Au}-2$ was collected from the drill core 56ZK23 at $402 \mathrm{~m}$ depth that crosscuts orebody KT57 (Fig. 1b). Au-1 consists of abundant magnetite, quartz, subordinate pyrite, and chalcopyrite, while $\mathrm{Au}-2$ is mainly composed of magnetite, pyrite, chalcopyrite, chlorite, biotite, siderite, and quartz. The Au grades (fire assay) for $\mathrm{Au}-1$ and $\mathrm{Au}-2$ are 15.3 and $25.5 \mathrm{~g} / \mathrm{t}$, but a nugget effect cannot be ruled out as only small chips were assayed for each sample.

\section{Methodology}

FIB/SEM and TEM analyses were conducted at the GFZ German Research Centre for Geosciences, Potsdam, Germany. Eight magnetite foils $(\sim 15 \times 10 \times$ $0.15 \mu \mathrm{m}$ for each) were cut from three polished thin sections with a FEI Helios G4 UC Dual Beam FIB using a Ga ion source. The surfaces of interest were covered with thin, Pt-protective layers followed by sputtering material out in front and sides by Ga ions at a $30 \mathrm{kV}$ voltage and a $47 \mathrm{nA}$ current. The front side of each foil was subsequentially milled by Ga ions under a $2.5 \mathrm{nA}$ current. All FIB foils were finally polished at $5 \mathrm{kV}$ and $41 \mathrm{pA}$ to remove re-deposited material. The detailed procedures of cutting a FIB foil were described by Wirth $(2004,2009)$. The FIB foils were fixed in the $\mathrm{Cu}$-grids and were not carbon-coated. A FEI Tecnai G2 F20 $\mathrm{X}$-Twin TEM, equipped with a high-angle annular dark-field (HAADF) detector and an energy-dispersive X-ray spectroscopy (EDX), was employed to investigate the foils at a $200 \mathrm{kV}$ voltage. The diffraction patterns (fast Fourier transformation, FFT) were calculated from the high-resolution lattice fringes images. The sizes and numbers of nanopores were measured using the software ImageJ.

Three-dimensional (3D) tomography in this study was based on the slice and view technology of the dual-beam (FIB/SEM) systems. After careful examination under the backscattered electron (BSE) mode and with EDX, a magnetite grain

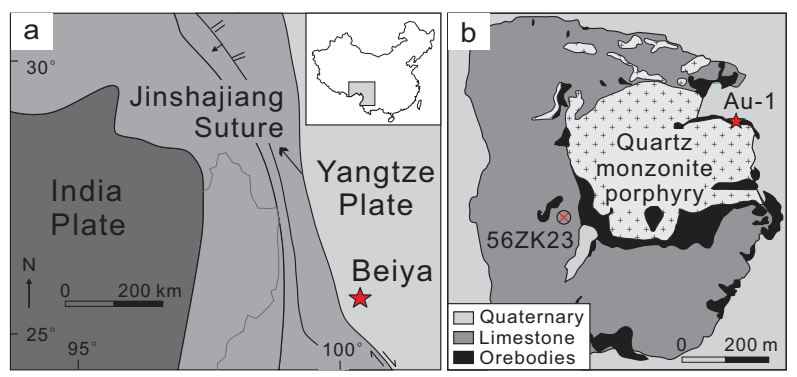

Figure 1. (a) Simplified geological map of Southwest China. (b) Geological map of the Beiya deposit (after He et al. 2017) and locations of investigated samples and drill core. bearing only gold nanoparticles was selected. A $0.7 \mu \mathrm{m}$ carbon-protective layer was coated on the surface of the region of interest. The front and lateral material of the target were removed by Ga ion sputtering to produce a cubic volume of $\sim 15 \times 15 \times 15 \mu \mathrm{m}^{3}$. Based on the beam geometries in the dual-beam systems, the sample was tilted with an angle of $54^{\circ}$. The voltage and current were $5 \mathrm{kV}$ and $50 \mathrm{nA}$ for the electron beam and were $30 \mathrm{kV}$ and $0.23 \mathrm{nA}$ for the ion beam. An automatic protocol of slice-cutting followed by SEM-imaging on the surface of cross sections was applied to produce the FIB-SEM tomograms. The slice distance was set at $17.6 \mathrm{~nm}$, and a stack of 991 SEM images were obtained using an E-T detector. The $3 \mathrm{D}$ reconstruction was conducted with the software Avizo 7.0, but only the middle 600 SEM images were loaded to maximize the overlapping areas. Because of the low contrast of some nanopores to the background, the reconstructed results display locally high noise for nanopores. Except for this, the rendered nanopores basically match their distribution in the 2D SEM images.

\section{Results}

\section{Microstructure in magnetite}

Two types of magnetite were defined in this study: silician and low-Si magnetite (Figs. 2 and 3). Specifically, silician magnetite is euhedral, nonporous, and devoid of mineral inclusions. It shows oscillatory zoning in the BSE images (Fig. 2a) but has Si contents that can be measured by EDX (Fig. 3b). In contrast, low-Si magnetite is brighter in the BSE images (Figs. 2a-2c) and has no detectable Si (Fig. 3b). It occurs as irregular domains within, or penetrating, through the silician magnetite (Figs. 2a-2c). Bright-field (BF) imaging across the interface of the two magnetite types shows that they have the same crystallographic orientation (like a single crystal; Fig. 2f). The low-Si magnetite is characterized by high porosity (Figs. 2a-2c), with a local mean pore size down to $5 \mathrm{~nm}(\mathrm{n}=1241$; Figs. $4 \mathrm{a}$ and 4b); some nanopores have a rhombic morphology (Fig. 4a). In the $3 \mathrm{D}$ image, these nanopores are partially interconnected (Fig. 5; Video ${ }^{1}$ V1). The nanopores are empty (Fig. 6c) or filled with Si-bearing phases (Fig. 6d). Abundant nanometer-sized Au and $\mathrm{Bi}$ phases (e.g., native bismuth, maldonite, bismuthinite, galenobismutite, and $\mathrm{Bi}-\mathrm{Pb}-\mathrm{Ag}$ sulfosalts) are present in the nanopores in low-Si magnetite, with the $\mathrm{Bi}$ phases dominated by Bi-sulfides and -sulfosalts (Figs. 3 and 7a).

\section{Gold nanoparticles}

Gold occurs as submicrometer- to nanometer-sized grains that can be as small as $\sim 5 \mathrm{~nm}$ (Figs. 2-7; Video ${ }^{1} \mathrm{~V} 2$ ). The HAADF and $\mathrm{BF}$ images show that gold nanoparticles are attached to nanopores in the low-Si magnetite (Figs. 2, 3, 5, and 6; Video $^{1}$ V3). In the $2 \mathrm{D}$ images, the morphology of the gold nanoparticles is elongate (Fig. 6a), triangular (Fig. 2d) or hexagonal (Fig. 6f). In the 3D images, gold is present as octahedral or flat nanoparticles in the low-Si magnetite and, interestingly, most flat gold nanoparticles are oriented (Fig. 5; Video ${ }^{1}$ V2). Clusters of gold nanoparticles can occur alone in a single grain of low-Si magnetite (Fig. 2b), but are always accompanied by nanoparticle assemblages of $\mathrm{Bi}$ phases (e.g., native bismuth, bismuthinite) several ten to hundreds of micrometers away (Fig. 2a). The gold nanoparticles have sharp contacts with native bismuth as well as maldonite (Figs. $7 \mathrm{~b}$ and $7 \mathrm{c}$ ). The high-resolution TEM (HRTEM) images display two distinct orientation types of the gold nanoparticles in the host magnetite: (1) an orientation relationship, where (111) planes of gold are parallel to (111) planes of magnetite (Fig. 6h), and (2) random orientation of gold grains (Fig. 6i). In the first case, the gold nanoparticles are always elongate and occur along 

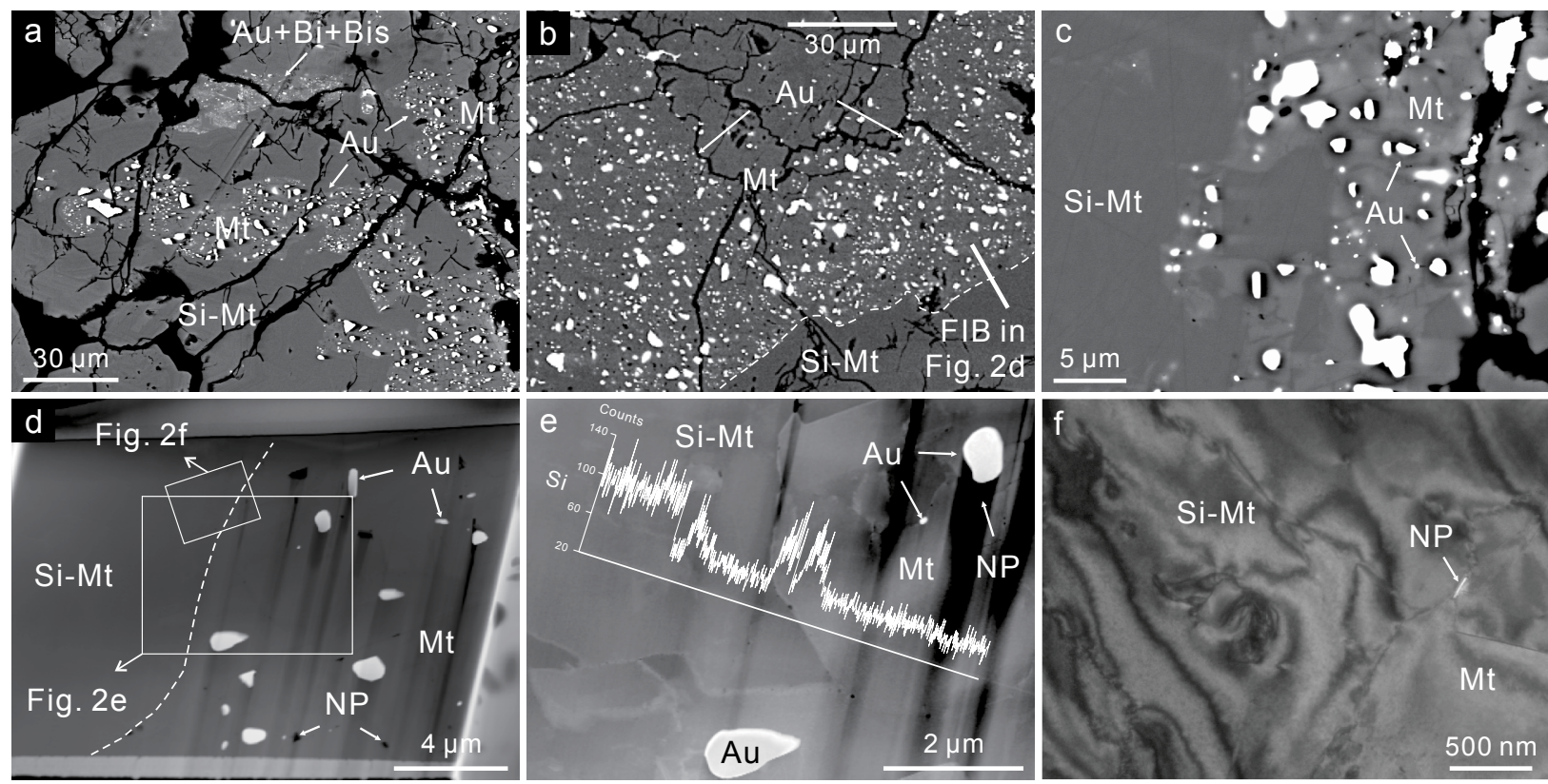

FIGURE 2. (a-c) BSE images showing porous low-Si magnetite (Mt) occurring as irregular domains within or penetrating euhedral, nonporous silician magnetite (Si-Mt). The former is of higher BSE intensities and rich in two types of nanoparticle clusters: (1) gold nanoparticles and (2) assemblages of gold, native bismuth (Bi) and bismuthinite (Bis). Note the oscillatory zonation in silician magnetite in a. (d and e) HAADF images of a FIB foil (location marked in b) showing the association of gold and nanopores (NP) with low-Si magnetite. EDX line scan (white solid line) across the contact zone in e displaying large variations in Si contents. (f) BF image across the contact of two types of magnetite illustrating a topotactic reaction.
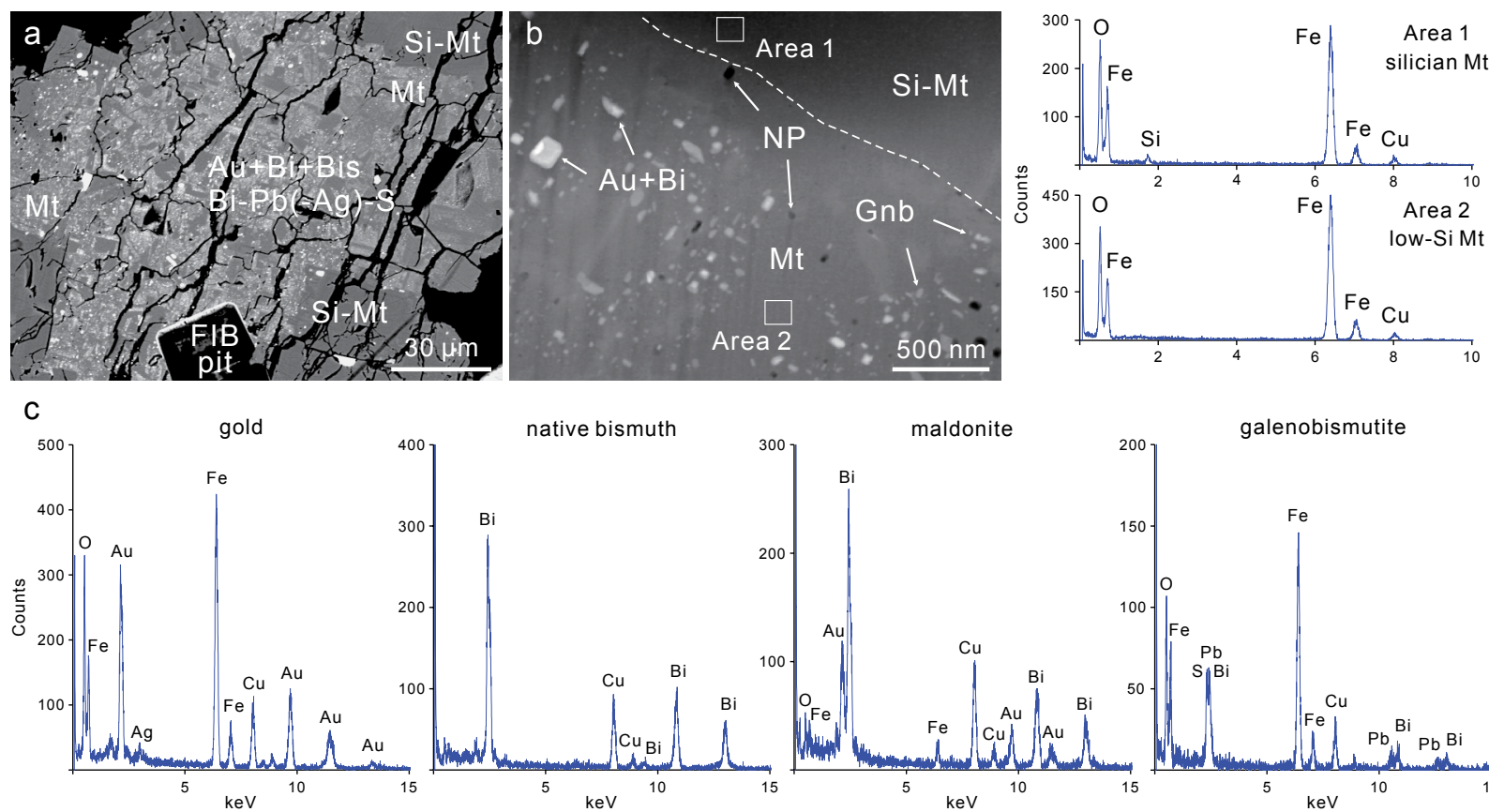

FigUrE 3. (a) BSE image showing silician magnetite (Si-Mt) replaced by low-Si magnetite (Mt) that is rich in assemblages of gold, native bismuth (Bi), bismuthinite (Bis), and Bi-Pb(-Ag)-S. (b) HAADF image and EDX spectra of two magnetite types in a FIB foil (location marked in a) showing abundant nanoparticles of gold, native bismuth, and galenobismutite (Gnb) in low-Si magnetite. (c) Representative EDX spectrum of the nanoparticles of the Au and Bi phases in low-Si magnetite. 

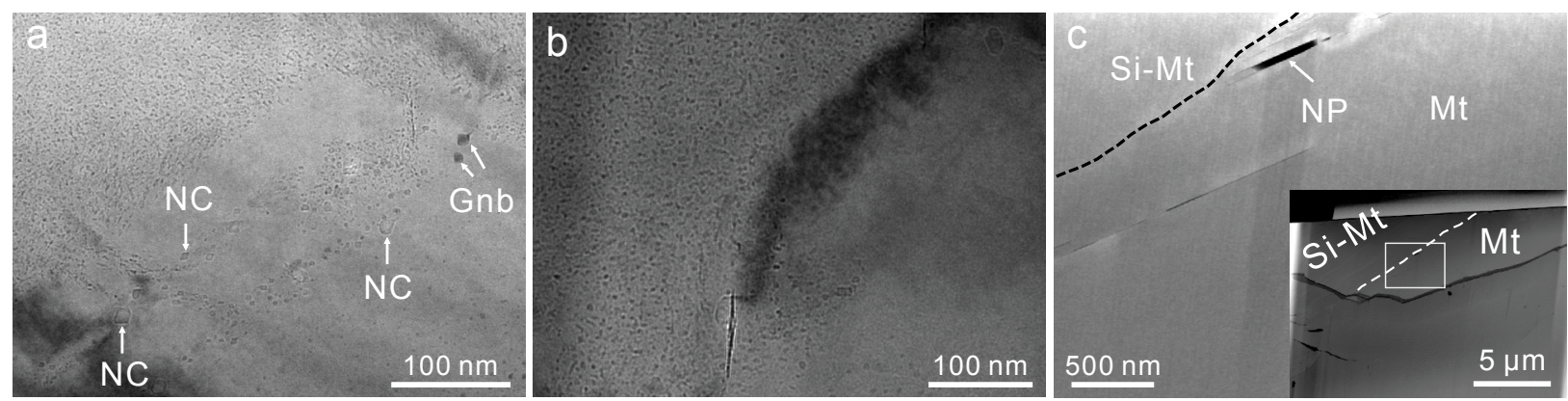

FigURE 4. (a and b) BF images showing the (locally) high porosity in low-Si magnetite (Mt). Note that the mean size of nanopores (NP) in the upper-left part in a is $5 \mathrm{~nm}(\mathrm{n}=1241)$ and some nanopores show negative crystals $(\mathrm{NC})$ with rhombic shapes. Other abbreviations: Gnb $=$ galenobismutite. (c) HAADF images of a FIB foil showing low-Si magnetite contacting with silician magnetite (Si-Mt). Note that there are few nanopores and no Au nanoparticle in low-Si magnetite.
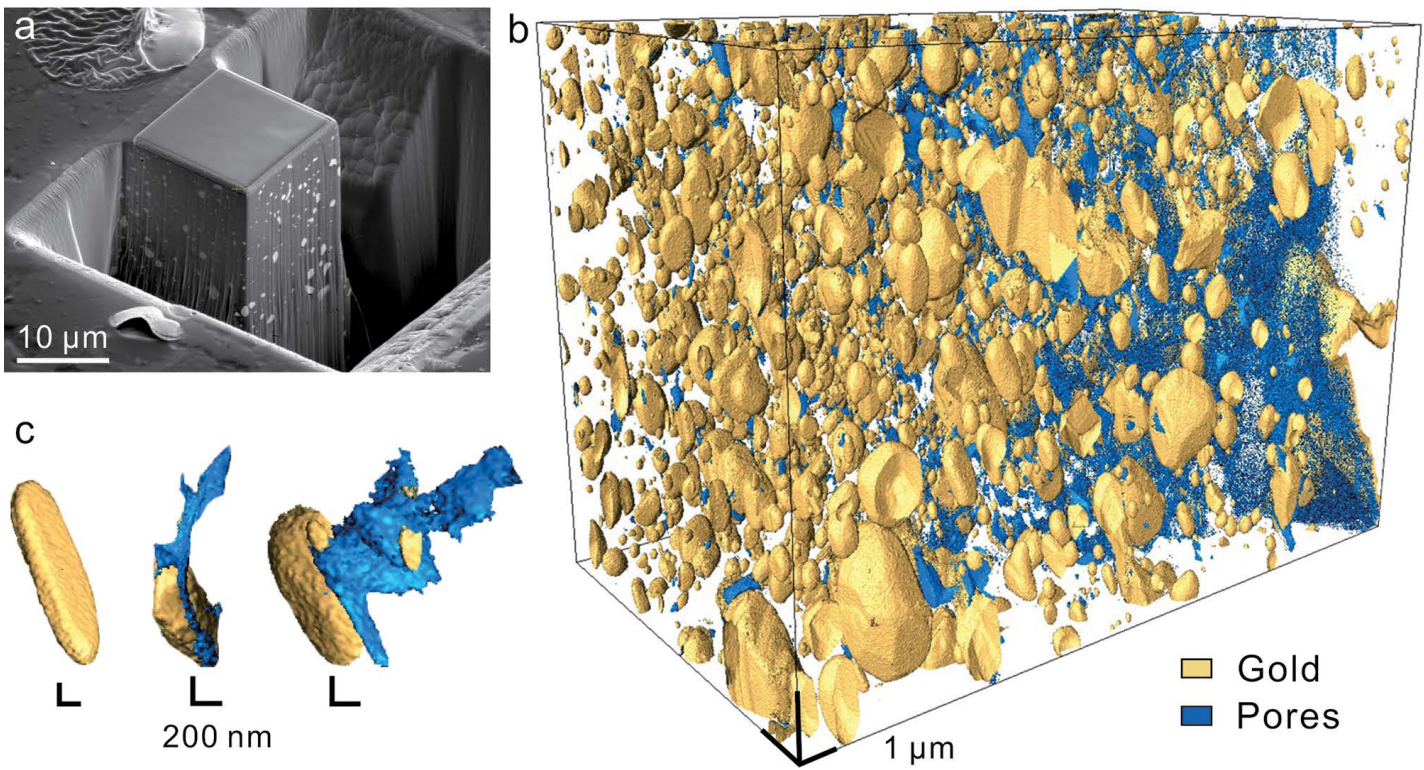

FIGURE 5. (a) SEM images of a cubic volume of gold-rich (the bright spots) low-Si magnetite that was FIB-sliced for 3D SEM tomography. (b) 3D rendering illustrating association of gold and nanopores in low-Si magnetite. (c) Examples of gold nanoparticles attached to interconnected nanopores.

sub-grain boundaries (low-angle boundaries) separated by defects in magnetite (Fig. 6g). In contrast, randomly oriented gold nanoparticles are located along sub-grain boundaries of magnetite or within the magnetite sub-grains.

\section{Discussion}

In ore systems, gold nanoparticles are always present in refractory ores most commonly in As-bearing Fe-sulfides, e.g., (arsenian) pyrite and arsenopyrite (Palenik et al. 2004; Reich et al. 2006). Although Zhou et al. (2017) described submicrometersized gold particles in magnetite, their morphology, and their mineralogical relationship to the magnetite, was ambiguous due to the limited resolution of 2D SEM. Therefore, the mechanism by which the magnetite incorporated a large number of gold particles was unknown. Here, we present the high-resolution TEM and 3D morphological images of "invisible" gold in magnetite, which is the first application of the FIB/SEM slice and view technology to the study of "invisible" gold in an ore mineral.

In 2D some of the gold nanoparticles appear to be fully en- closed in magnetite but, in fact, are linked to nanopores in the third dimension (Fig. 5c). The 3D image also displays that the nanopores are interconnected to some extent (Fig. 5b), which suggests that they denote channels of migrating fluids (e.g., Harlov et al. 2005; Birski et al. 2018). Therefore, we argue that the gold nanoparticles were precipitated from a fluid phase, rather than non-fluid mediated exsolution from the host low-Si magnetite.

\section{Coupled dissolution-reprecipitation reaction making magnetite porous}

The textural relationships suggest that the silician magnetite is replaced by the low-Si magnetite (Figs. 2a-2c). We note that (1) the late low-Si magnetite has high porosity, while the early silician magnetite is less porous; (2) the contacts are sharp between the two magnetite types; and (3) the same crystallographic orientation between the two magnetite types indicates a topotactic reaction, i.e., the orientation of the low-Si magnetite depends on the already existing silician magnetite. These are diagnostic features for the low-Si magnetite formed by a coupled 
dissolution-reprecipitation reaction (CDRR; Putnis 2002; AltreeWilliams et al. 2015). This is a fluid-mediated process that typically involves the dissolution of a parent mineral (i.e., the silician magnetite) followed by reprecipitation of a stable product phase (i.e., the low-Si magnetite) at the reaction front (Putnis 2002; Altree-Williams et al. 2015; Yin et al. 2019). Silician magnetite is of higher lattice energy relative to low-Si magnetite, so a fluid phase in disequilibrium with silician magnetite can drive the CDRR to decrease the Gibbs free energy of minerals (Putnis 2002; Dubacq and Plunder 2018).

Studies documenting CDRR in magnetite of skarn systems attribute the process to changes in oxygen fugacity $\left(f_{\mathrm{O}_{2}}\right)$, temperature, salinity, and pressure of the fluids (e.g., Hu et al. 2015). In the Beiya skarn ores, the newly formed low-Si magnetite always occurs as irregular domains in the silician magnetite. The lack of a low-Si magnetite overgrowth on the silician magnetite suggests that the fluids responsible for CDRR probably did not cause significant new magnetite formation and the elements required for precipitation of the low-Si magnetite predominantly came from the dissolution of the early silician magnetite. Given the abundant Bi-sulfide and -sulfosalt nanoparticles (e.g., bis- muthinite, galenobismutite, $\mathrm{Bi}-\mathrm{Pb}-\mathrm{Ag}-\mathrm{S}$ phases) in the low-Si magnetite, we argue that the CDRR probably took place at the transition from the oxide- to sulfide-stages during the evolution of the Beiya hydrothermal system. The transition was caused by cooling and the influx of meteoric water (He et al. 2017) and was accompanied with changes in fluid thermodynamic conditions, e.g., a decrease in temperature, salinity (He et al. 2017) and an increase in (reduced) S content (Seo et al. 2009). We suggest that these thermodynamic changes gave rise to the dissolution of the silician magnetite followed by supersaturation with respected to purer (low-Si) magnetite.

Formation of numerous pores in product minerals is an important feature for CDRR, which results from volume reduction of the product phases and allows the propagation of the reaction front toward the parent minerals (Putnis 2002; Ruiz-Agudo et al. 2014). The porous texture offers critical spaces for the nucleation and growth of gold nanoparticles inside the low-Si magnetite. For comparison, another FIB foil of the low-Si magnetite with few nanopores is devoid of gold nanoparticles (Fig. 4c). Another expectation is that the interconnectivity of nanopores in the low-Si magnetite was reduced due to progressive re-equilibration,
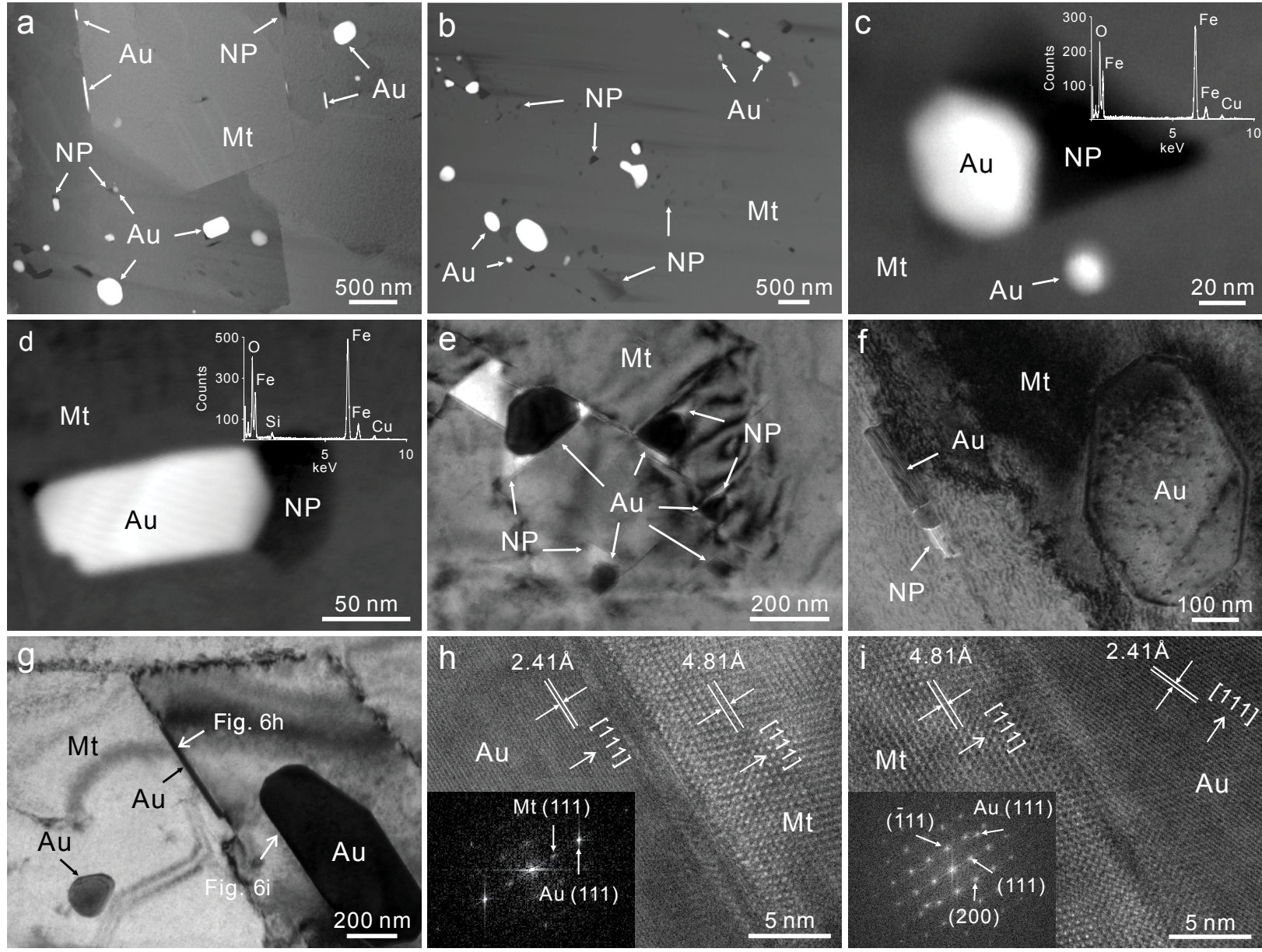

FigURE 6. (a-d) HAADF images showing gold nanoparticles and nanopores (NP) in low-Si magnetite (Mt). Note that the EDX spectra of the nanopores are shown at the top-right in $\mathbf{c}$ and $\mathbf{d}$. (e) BF image of nanopore-attached gold nanoparticles. (f and g) BF images showing elongate gold nanoparticles along the low-angle boundaries and spheroidal gold nanoparticles within magnetite sub-grains. (h and i) HRTEM images showing interfaces of the elongate (h) and spheroidal (i) gold nanoparticles with low-Si magnetite. The FFT is inserted at the bottom-left. 

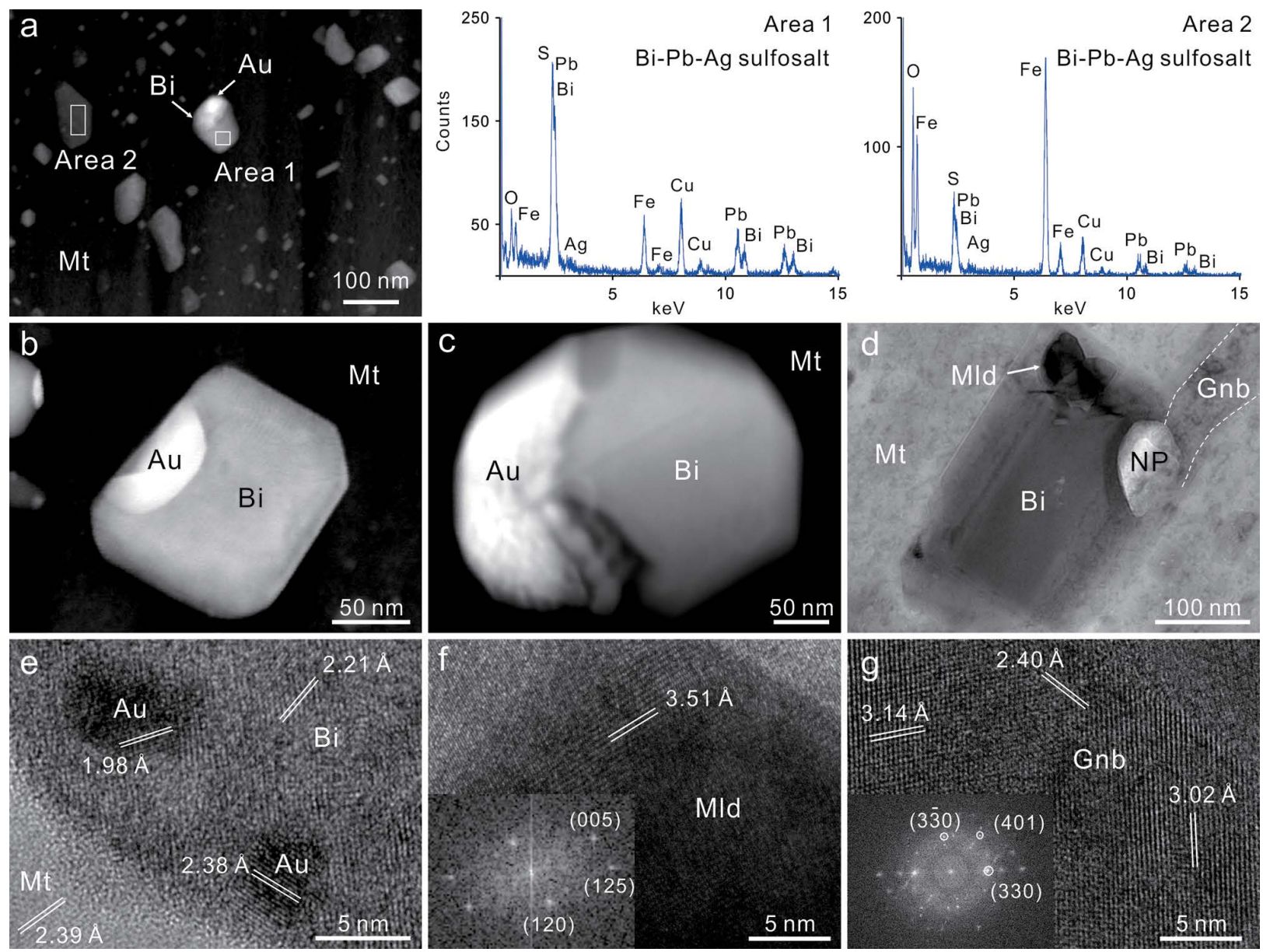

FigURE 7. (a-c) HAADF images of nanometer-sized blebs of gold + native bismuth (Bi) and EDX spectrum of Bi-Pb-Ag sulfosalts. Note the overwhelming amounts of $\mathrm{Bi}-\mathrm{Pb}-\mathrm{Ag}$ sulfosalts in the low-Si magnetite and the sharp contacts between gold and native bismuth. (d) BF image of maldonite (Mld) + native bismuth bleb attached to a nanopore (NP) and altered by galenobismutite (Gnb) in low-Si magnetite (Mt). (e-g) HRTEM images and FFT of gold + native bismuth, maldonite, and galenobismutite in low-Si magnetite.

especially behind the reaction front. Some nanopores may have been annealed out by fluids due to Ostwald ripening (Ruiz-Agudo et al. 2014). This is consistent with the partially interconnected nanopores revealed by the 3D FIB/SEM tomography.

\section{Growth of gold nanoparticles from Au-supersaturated fluids in nanopores}

The two observed orientation relationships between the gold nanoparticles and low-Si magnetite represent two different nucleation and growth mechanisms for gold nanoparticles. The parallel orientation relationship suggests the heteroepitaxial growth of elongate gold nanoparticles on the low-Si magnetite surfaces. The $d$-spacing of (111) planes for gold is $2.36 \AA$, approximately half of the $d$-spacing of (111) planes for magnetite ( $4.85 \AA$ ). In this case, the measured $d$-spacings of the (111) planes for gold and host magnetite are 2.41 and $4.81 \AA$ (Figs. 6h), supporting such a scenario. This growth pattern compensates the lattice mismatch between the two different solid phases and minimizes the lattice strain energy (Zheleva et al. 1994). Moreover, the (111) crystal-

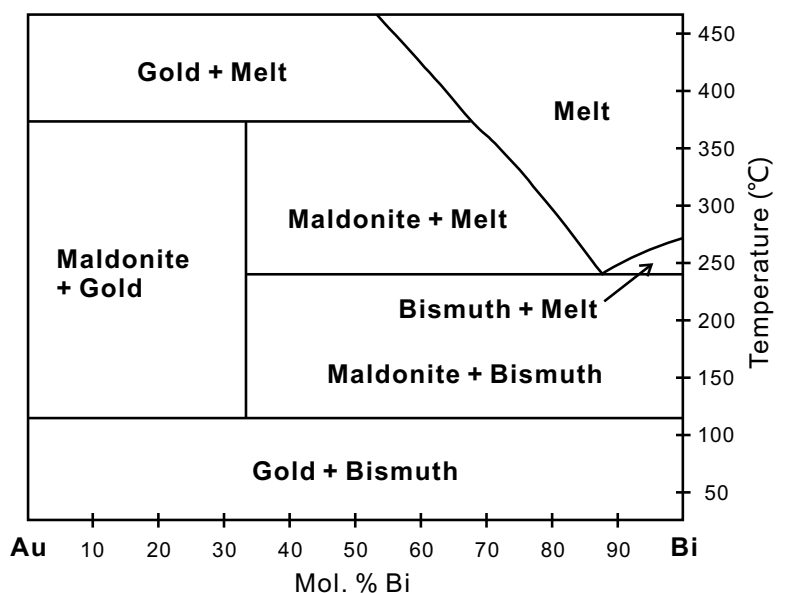

FigURE 8. Binary Au-Bi phase diagram illustrating the solubility of $\mathrm{Au}$ in $\mathrm{Bi}$ melt as well as eutectics in the Au-Bi system (after Okamoto and Massalski 1983). 

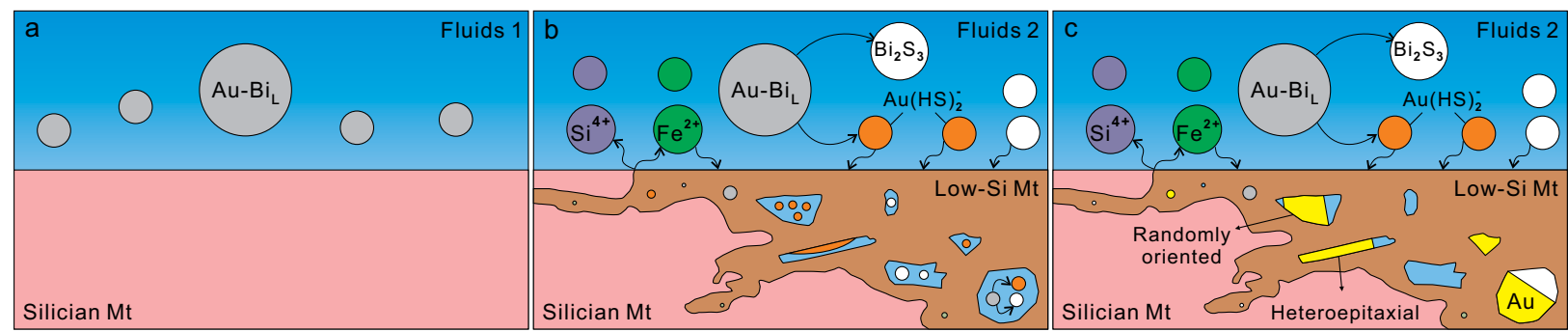

FIGURE 9. Schematic illustration of gold nanoparticle formation at mineral-fluid interfaces. (a) Crystallization of silician magnetite from fluids that carried nano-sized $\mathrm{Au}-\mathrm{Bi}$ melts. (b) CDRR on silician magnetite surfaces forming porous low-Si magnetite and causing the disequilibrium of Au-Bi melts that formed Au-supersaturated fluids at the pore-scale. (c) Heteroepitaxial and randomly oriented growth of gold nanoparticles in nanopores of low-Si magnetite.

lographic plane of magnetite with the highest surface energy is where nucleation would happen preferentially (Jia and Gao 2008). It has been suggested that if the contact angle of crystals (e.g., the gold nanoparticles) and the pore wall is small, the pore wall can be an effective nucleating agent (Scherer 1999). In this case, gold nanoparticles would nucleate from the pore-fluids using the magnetite lattice parallel to the (111) lattice planes. This can explain the oriented alignment of the flat gold nanoparticles in the low-Si magnetite observed from the 3D images. The flat planes of the gold nanoparticles probably result from the preferential growth of the (111) lattice planes.

In contrast, the second type of gold nanoparticles had random orientation relationships with the magnetite, indicating that they nucleated and grew with little or no contact with magnetite surfaces. This is because these pore walls are not favorable nucleation sites due to their large contact angles with the crystals (Scherer 1999). Hence, the diversity of nucleation and growth orientation types resulted from intrinsic factors such as crystal structure and pore textures of gold and magnetite at fluid-mineral interfaces.

Immiscible Bi melts can directly fractionate and effectively collect (ionic) gold from coexisting fluids, forming Au-Bi melts (Tooth et al. 2008, 2011). In this study, rare nanometer-sized Au-Bi blebs of native bismuth + gold and native bismuth + maldonite have sharp contacts and are interpreted as eutectic alloys from nanometer-scaled Au-Bi melts (Figs. 7b-7c and 8). Although these Au-Bi blebs were found in the low-Si magnetite, their stability was not thermodynamically supported by the highly reduced sulfur in the hydrothermal fluids responsible for CDRR (Zhou et al. 2017). Because Bi commonly exists as a trivalent oxidation state in the fluids (Tooth et al. 2011), the fractionation of Au-Bi melts from the hydrothermal fluids at Beiya has been attributed to an early decrease in $f_{\mathrm{O}_{2}}$ to below the hematite-magnetite buffer (Zhou et al. 2017), which resulted in the onset of magnetite crystallization. Given the overwhelming abundance of Bi-sulfides and sulfosalts compared to native bismuth or maldonite in the low-Si magnetite (Figs. $3 \mathrm{~b}$ and $7 \mathrm{a}$ ) and the replacement texture of the Au-Bi blebs by Bi-sulfides and sulfosalts (Figs. 7a and 7d), we suggest that these $\mathrm{Au}-\mathrm{Bi}$ blebs represent the relicts of Au-Bi melts that should have been coeval with the early silician magnetite (Fig. 9a). Although the $\mathrm{Au}-\mathrm{Bi}$ melt droplets would have a high density, we argue that they were poorly separated from the fluids due to the high surface tension of the nanoparticles. Similar Bi melt droplets trapped in fluid inclusions have been found in an iron oxide copper-gold (IOCG) deposit (Acosta-Góngora et al. 2015). The poor separation of melt droplets from fluids is favorable for Au refining by the suspended Bi melts, a process previously identified at Beiya (Zhou et al. 2017).

It is probable that the variations in thermodynamic conditions responsible for CDRR in magnetite also accounted for the disequilibrium of Au-Bi melts (Fig. 9b), given the accumulation of Bi-Au assemblages at the reaction front in magnetite (Fig. 3b). Thermodynamically, $\mathrm{Bi}^{0}$ was converted to bismuthinite (or other $\mathrm{Bi}$ sulfides such as galenobismutite if $\mathrm{Pb}$ was present) when the temperature dropped and reduced $\mathrm{S}$ content increased (Zhou et al. 2017). The solubility of Au is extremely high in Bi melts (up to $\sim 35 \mathrm{wt} \%$ at $400{ }^{\circ} \mathrm{C}$; Fig. 8), but is much lower in geological fluids (ppb-level; Williams-Jones et al. 2009). Nanoparticles are always formed from the supersaturated fluids, where nucleation rates are much higher than growth rates (e.g., Hochella et al. 2008). Therefore, we argue that the disequilibrium of $\mathrm{Au}-\mathrm{Bi}$ melts released $\mathrm{Au}$ into fluids, resulting in the formation of local (pore-scale) Au-supersaturated fluids from which the gold nanoparticles in the low-Si magnetite crystallized (Fig. 9c).

\section{IMPLICATIONS}

Two generations of magnetite (nonporous silician and porous low-Si) are interpreted to result from CDRR at the ore stage in the world-class Beiya Au deposit, Southwest China. We have presented the first 3D FIB/SEM tomography of abundant gold nanoparticles in the nanopores of the low-Si magnetite. We argue that the gold nanoparticles crystallized from $\mathrm{Au}$-supersaturated fluids that originated from the disequilibrium of Au-Bi melts. We illustrate the role of intrinsic (e.g., crystal structure and pore textures) and extrinsic factors (e.g., reduced S content and temperature) in the formation of gold nanoparticles at fluidmineral interfaces.

Non-lattice-bound "invisible" gold in mineral deposits is commonly interpreted to be remobilized from the exsolution of earlier formed minerals (e.g., Large et al. 2007; Sung et al. 2009; Cook et al. 2013). However, our work offers an alternative explanation in that this gold can also be introduced by later hydrothermal fluids during progressive mineralization. In addition, this study indicates that "invisible" gold nanoparticles in ore minerals, perhaps not solely in magnetite, may result from nanoscale permeability between nanopores developed from CDRR on earlier minerals. 


\section{ACKNOWLedgments AND Funding}

We are grateful to Denis Fougerouse and three anonymous reviewers for their critical comments on the manuscript. The German Academic Exchange Service (DAAD) is thanked for funding Haoyang Zhou's stay at GFZ. Sarah A. Gleeson and Sathish Mayanna acknowledge the financial support of the Helmholtz Recruiting Initiative (No. 0316 and I-044-16-01, respectively).

\section{REFERENCES CITED}

Acosta-Góngora, P., Gleeson, S.A., Samson, I.M., and Ootes, L.C. (2015) Gold refining by bismuth melts in the iron oxide-dominated NICO Au-Co-Bi $( \pm \mathrm{Cu} \pm \mathrm{W})$ deposit, NWT, Canada. Economic Geology, 110, 291-314.

Altree-Williams, A., Pring, A., Ngothai, Y., and Brugger, J. (2015) Textural and compositional complexities resulting from coupled dissolution-reprecipitation reactions in geomaterials. Earth-Science Reviews, 150, 628-651.

Birski, Ł., Wirth, R., Słaby, E., Wudarska, A., Lepland, A., Hofmann, A., and Schreiber, A. (2018) (Ca-Y)-phosphate inclusions in apatite crystals from Archean rocks from the Barberton Greenstone Belt and Pilbara Craton: First report of natural occurrence. American Mineralogist, 103, 307-313.

Ciobanu, C.L., Cook, N.J., Utsunomiya, S., Kogagwa, M., Green, L., Gilbert, S., and Wade, B. (2012) Gold-telluride nanoparticles revealed in arsenic-free pyrite. American Mineralogist, 97, 1515-1518.

Cook, N.J., and Chryssoulis, S.L. (1990) Concentrations of invisible gold in the common sulfides. Canadian Mineralogist, 28, 1-16.

Cook, N.J., Ciobanu, C.L., Meria, D., Silcock, D., and Wade, B. (2013) Arsenopyritepyrite association in an orogenic gold ore: Tracing mineralization history from textures and trace elements. Economic Geology, 108, 1273-1283.

Dubacq, B., and Plunder, A. (2018) Controls on trace element distribution in oxides and silicates. Journal of Petrology, 59, 233-256.

Fougerouse, D., Reddy, S.M., Saxey, D.W., Rickard, W.D.A., Riessen, A.V., and Micklethwaite, S. (2016) Nanoscale gold clusters in arsenopyrite controlled by growth rate not concentration: Evidence from atom probe microscopy. American Mineralogist, 101, 1916-1919.

Godel, B., Barnes, S.J., Barnes, S., and Maier, W.D. (2010) Platinum ore in three dimensions: Insights from high-resolution X-ray computed tomography. Geology, 38, 1127-1130.

Harlov, D.E., Wirth, R., and Förster, H. (2005) An experimental study of dissolutionreprecipitation in fluorapatite: fluid infiltration and the formation of monazite. Contributions to Mineralogy and Petrology, 150, 268-286.

He, W.Y., Yang, L.Q., Brugger, J., McCuaig, T.C., Lu, Y.J., Bao, X.S., Gao, X.Q., Lu, Y.G., and Xing, Y.L. (2017) Hydrothermal evolution and ore genesis of the Beiya giant Au polymetallic deposit, western Yunnan, China: Evidence from fluid inclusions and $\mathrm{H}-\mathrm{O}-\mathrm{S}-\mathrm{Pb}$ isotopes. Ore Geology Reviews, 90, 847-862.

Hochella, M.F., Lower, S.K., Maurice, P.A., Penn, R.L., Sahai, N., Sparks, D.L., and Twining, B.S. (2008) Nanominerals, mineral nanoparticles, and Earth systems. Science, 319, 1631-1635.

Hu, H., Lentz, D., Li, J.W., McCarron, T., Zhao, X.F., and Hall, D. (2015) Reequilibration processes in magnetite from iron skarn deposits. Economic Geology, $110,1-8$.

Jia, B.P., and Gao, L. (2008) Morphological transformation of $\mathrm{Fe}_{3} \mathrm{O}_{4}$ spherical aggregates from solid to hollow and their self-assembly under an external magnetic field. The Journal of Physical Chemistry C, 112, 666-671.

Kusebauch, C., Gleeson, S.A., and Oelze, M. (2019) Coupled partitioning of Au and As into pyrite controls formation of giant Au deposits. Science Advances, 5 , eaav5891.

Large, R.R., Maslennikov, V.V., Robert, F., Danyushevsky, L.V., and Chang, Z. (2007) Multistage sedimentary and metamorphic origin of pyrite and gold in the giant Sukhoi Log deposit, Lena gold province, Russia. Economic Geology, $102,1233-1267$

Mao, J.W., Zhou, Y.M., Liu, H., Zhang, C.Q., Fu, D.G., and Liu, B. (2017) Metallogenic setting and ore genetic model for the Beiya porphyry-skarn polymetallic Au orefield, western Yunnan, China. Ore Geology Reviews, 86, 21-34.

Okamoto, H., and Massalski, T.B. (1983) The Au-Bi (gold-bismuth) system. Bulletin of Alloy Phase Diagrams, 4, 401-407.

Palenik, C.S., Utsunomiya, S., Reich, M., Kesler, S.E., Wang, L., and Ewing, R.C. (2004) "Invisible" gold revealed: Direct imaging of gold nanoparticles in a Carlin-type deposit. American Mineralogist, 89, 1359-1366.

Putnis, A. (2002) Mineral replacement reactions: from macroscopic observations to microscopic mechanisms. Mineralogical Magazine, 66, 689-708.
Reich, M., Kesler, S.E., Utsunomiya, S., Palenik, C.S., Chryssoulis, S.L., and Ewing, R.C. (2005) Solubility of gold in arsenian pyrite. Geochimica et Cosmochimica Acta, 69, 2781-2796.

Reich, M., Utsunomiya, S., Kesler, S.E., Wang, L., Ewing, R.C., and Becker, U. (2006) Thermal behavior of metal nanoparticles in geologic materials. Geology, 34, 1033-1036.

Ruiz-Agudo, E., Putnis, C.V., and Putnis, A. (2014) Coupled dissolution and precipitation at mineral-fluid interfaces. Chemical Geology, 383, 132-146.

Scherer, G.W. (1999) Crystallization in pores. Cement and Concrete Research, 29, $1347-1358$.

Seo, J.H., Guillong, M., and Heinrich, C.A. (2009) The role of sulfur in the formation of magmatic-hydrothermal copper-gold deposits. Earth and Planetary Science Letters, 282, 323-328.

Simon, G., Huang, H., Penner-Hahn, J.E., Kesler, S.E., and Kao, L. (1999a) Oxidation state of gold and arsenic in gold-bearing arsenian pyrite. American Mineralogist, 84, 1071-1079.

Simon, G., Kesler, S.E., and Chryssoulis, S. (1999b) Geochemistry and textures of gold-bearing arsenian pyrite, Twin Creeks, Nevada; implications for deposition of gold in carlin-type deposits. Economic Geology, 94, 405-421.

Sung, Y.H., Brugger, J., Ciobanu, C.L., Pring, A., Skinner, W., and Nugus, M. (2009) Invisible gold in arsenian pyrite and arsenopyrite from a multistage Archaean gold deposit: Sunrise Dam, Eastern Goldfields Province, Western Australia. Mineralium Deposita, 44, 765-791.

Tooth, B., Brugger, J., Ciobanu, C., and Liu, W.H. (2008) Modeling of gold scavenging by bismuth melts coexisting with hydrothermal fluids. Geology, 36, 815-818.

Tooth, B., Ciobanu, C.L., Green, L., O'Neill, B., and Brugger, J. (2011) Bi-melt formation and gold scavenging from hydrothermal fluids: An experimental study. Geochimica et Cosmochimica Acta, 75, 5423-5443.

Williams-Jones, A.E., Bowell, R.J., and Migdisov, A.A. (2009) Gold in solution. Elements, 5, 281-287.

Wirth, R. (2004) Focused Ion Beam (FIB): A novel technology for advanced application of micro- and nanoanalysis in geosciences and applied mineralogy. European Journal of Mineralogy, 16, 863-876.

- (2009) Focused Ion Beam (FIB) combined with SEM and TEM: Advanced analytical tools for studies of chemical composition, microstructure and crystal structure in geomaterials on a nanometre scale. Chemical Geology, 261, 217-229.

Wu, Y.F., Fougerouse, D., Evans, K., Reddy, S.M., Saxey, D.W., Guagliardo, P., and Li, J.W. (2019) Gold, arsenic, and copper zoning in pyrite: A record of fluid chemistry and growth kinetics. Geology, 47, 641-644.

Xing, Y.L., Brugger, J., Tomkins, A., and Shvarov, Y. (2019) Arsenic evolution as a tool for understanding formation of pyritic gold ores. Geology, 47, 335-338.

Yin, S., Wirth, R., Ma, C.Q., and Xu, J.N. (2019) The role of mineral nanoparticles at a fluid-magnetite interface: Implications for trace-element uptake in hydrothermal systems. American Mineralogist, 104, 1180-1188.

Zheleva, T., Jagannadham, K., and Narayan, J. (1994) Epitaxial growth in largelattice-mismatch systems. Journal of Applied Physics, 75, 860-871.

Zhou, H.Y., Sun, X.M., Fu, Y., Lin, H., and Jiang, L.Y. (2016) Mineralogy and mineral chemistry of Bi-minerals: Constraints on ore genesis of the Beiya giant porphyryskarn gold deposit, southwestern China. Ore Geology Reviews, 79, 408-424.

Zhou, H.Y., Sun, X.M., Cook, N.J., Lin, H., Fu, Y., Zhong, R.C., and Brugger, J. (2017) Nano- to micrometer-scale particulate gold hosted by magnetite: A product of gold scavenging by bismuth melts. Economic Geology, 112, 993-1010.

Zhou, H.Y., Sun, X.M., Wu, Z.W., and Huang, Q. (2019) Timing of skarn gold deposition in the giant Beiya polymetallic gold deposit, southwest China: Constraints from in situ monazite SIMS U-Th-Pb geochronology. Ore Geology Reviews, 106, 226-237.

MANUSCRIPT RECEIVED JULY 1, 2020

MANUSCRIPT ACCEPTED AUGUST 19, 2020

Manuscript handled by Daniel Harlov

\section{Endnote:}

${ }^{1}$ Deposit item AM-21-17696, Video Materials (.mov). Deposit items are free to all readers and found on the MSA website, via the specific issue's Table of Contents (go to http://www.minsocam.org/MSA/AmMin/TOC/2021/Jan2021_data/ Jan2021_data.html). 